Article

\title{
Analysis of management of newborns with critical CHD at pre- operative stage
}

\author{
Berkin Turkulov', Altyn Aringazina², Kairat Kuatbekov², Vitalii Pak ${ }^{3}$, Ayat Assemov 4,* \\ 1 Kazakhstan Medical University "KSPH", berkin86@mail.ru , altyn.aringazina@gmail.com \\ 2 Center of Perinatology and Pediatric Cardiac Surgery; k.kuatbekov@mail.ru \\ 3 Fondazione Toscana Gabriele Monasterio, Department of Pediatric Cardiac Surgery; pakv2009@mail.ru \\ 4 Ayat Assemov; University of Groningen, ayat.asemov@gmail.com \\ * Correspondence: ayat.asemov@gmail.com , +77072053310
}

\begin{abstract}
Congenital heart defects (CHD) are the most common birth anomaly affecting approximately $1 \%$ of births and have a prevalence of about 5.8 per 1000 people. CHD is the most common congenital anomaly in newborn babies. Management of the newborn with CHD represents a frontier of clinical pediatric cardiology. Progress in diagnosis and surgical treatment of the individuals with a heart defect has progressed to the point that almost all heart defects can be significantly improved and treated.
\end{abstract}

Cardiovascular malformations account for about $10 \%$ of infant deaths and nearly half of all deaths from malformations

Keywords: CHD, newborn, management, organization, cardiac surgery

\section{Introduction}

Congenital heart defects (CHD) are the most common birth anomaly affecting approximately $1 \%$ of births and have a prevalence of about 5.8 per 1000 people. [1-6]

CHD is the most common congenital anomaly in newborn babies.7 Cardiac malformations have been produced in multiple experimental animal models, by perturbing selected molecules that function in the development pathways involved in myocyte specification, differentiation, or cardiac morphogenesis.[4,7] The precise genetic, epigenetic, environmental basis for various perturbations in the human heart is not fully understood yet. [4]

Management of the newborn with CHD represents a frontier of clinical pediatric cardiology. Progress in diagnosis and surgical treatment of the individuals with a heart defect has progressed to the point that almost all heart defects can be significantly improved and treated.

Cardiovascular malformations account for about $10 \%$ of infant deaths and nearly half of all deaths from malformations. $[5,6,8]$

Global needs from childhood to adulthood for those with CHD have been less well investigated despite significant risks of morbidity and mortality across the lifespan. Given the lack of epidemiological and longitudinal data on individuals of all ages with CHD,

especially in developing countries. 
Heart defects, in which the chances of surviving to the first year are negligible, are considered to be "critical congenital heart defects during the neonatal period".[9] The degree of "criticality" and the time during which life-threatening conditions develop depend on the type of congenital heart defects, background pathology, individual characteristics of the child, the timeliness of diagnosis and the adequacy of the medical care provided at the preoperative stage. Therefore, an important task is the earliest diagnosis of congenital heart defects. The early detection of any congenital malformation is based on well-organized monitoring of pregnant women with instrumental and laboratory screening. $[4,6,8,10,11]$

According to the literature, the average level of prenatal detection of congenital heart defects in Europe is 19-48\%, in specialized centers - 95\%.[12] In Kazakhstan, 8-9\% of children with congenital heart defects are born annually. In the third part of children with congenital heart disease, life-threatening conditions develop, which are characterized by the development of hypoxemic syndrome and heart failure and the average level of prenatal detection of congenital heart defects reaches $17.9 \%$.[13,14]

Improving the quality of medical care for patients with defects of the cardiovascular system directly affects the infant mortality rate in general. In this regard, an important role is given to the correct organizational construction of medical care for newborns with congenital heart defects at all stages: obstetrician - neonatologist - resuscitator - pediatric cardiologist - cardiac surgeon, which determines the relevance of such studies to reduce the risk of hospital mortality and mortality of children.

\section{Materials and Methods}

At the preliminary stage of the study, medical care was analyzed for all newborns with congenital heart defects born or hospitalized at the Center for Perinatology and Pediatric Cardiac Surgery, Almaty (CPPCS).

Criteria for inclusion in the study group: Informed consent of the child's parents or guardians; neonatal period (from the moment of birth to 28 days of life at full-term; at premature term - up to 44 weeks of post-conceptual age); the presence of critical congenital heart disease (CHD). Premature infants with hemodynamically significant ductus arteriosus were excluded from the study.

Data were collected: clinical and medical history, prenatal and postnatal echocardiography, electrocardiography, laboratory research, treatment, hospital mortality at the preoperative stage.

Comparison and analysis of data was performed in two groups of patients with critical congenital heart defects: the first 119 patients born in 2007-2010, the second - patients born from November 20, 2011 to December 29, 2018, 1,098 children were treated in CPPCS under the age of 1 year, 175 of which were newborns $(15.9 \%)$. Of the last 27 were limited to conservative treatment. Eight $(29.6 \%)$ of these patients died from hypoxia and / or heart failure, which were incompatible with life, as well as from congenital pathology of other organs and systems. In the remaining 148 (81.7\%) cases, various surgical interventions were performed. The allocation of periods is due to a change in approaches to organizing MC for newborns with CHD in the period from 2011 and the opening of CPPCS.

Processing of the primary material was carried out using the methods of medical statistics and the software package SPSS 21 and MS Excel. To assess the quantitative indica- 
tors were calculated: median and interquantile range in the form of 25 and 75 percentiles, the average value and standard error. The description of the qualitative indicators of the sample was carried out by calculating the absolute quantity, fraction and standard error of the fraction. To compare the values of indicators in the groups, the method of nonparametric statistics, the KJ-Mann-Whitney test, was used; to characterize differences in qualitative characteristics in different subgroups - Pearson's criterion. The critical value of the significance level was taken equal to 0.05 . Differences were considered statistically significant at $\mathrm{p}<0.05$

\section{Results}

In the period from 2007 to 2010, the system of providing MC was traditional. In antenatal clinics, prenatal ultrasound (US) screening of pregnant women was carried out on maternity leave in 3 stages (10-14 weeks, 20-24 weeks, 30-34 weeks). If a fetal CHD was suspected, the woman was sent for an ultrasound study to regional perinatal centers. In the diagnosis of critical CHD, the child was transported by an on-site advisory resuscitation neonatal team to the neonatology departments of hospitals in accordance with the consolidation of territories. Echocardiography was performed on an ultrasound machine of the expert class. The newborn was examined by a heart surgeon and, if necessary, an emergency or urgent surgical intervention was sent to the National Scientific Center of Surgery named after A.N. Syzganova or was sent outside the Republic of Kazakhstan.

Since 2011, prenatal echocardiography of the fetus has been predominantly performed in the consultative clinic of the CPPCS or the City Center for Human Reproduction in Almaty. During this period, the opportunity and need for echocardiography of the fetus appeared earlier (16-18 weeks). During prenatal detection of CHD in the fetus, a pregnant woman was observed and was sent for delivery to the CPPCS, which includes a neonatal intensive care unit, neonatologists, cardiologists and a cardiac surgical team who are skilled in delivering emergency MC to a newborn with critical CHD MC according to the profile "cardiovascular surgery". Neonatologists conducted a screening study of newborns to detect CHD, which included a physical examination, auscultation of the heart and blood vessels to detect noise, an assessment of saturation, blood pressure and pulse characteristics in the lower and upper extremities. In cases of suspected CHD, children were consulted by a pediatric cardiologist or cardiac surgeon (which is possible in perinatal centers), and echocardiography was performed. Since 2011, an integrated approach has been put into practice in determining the timing, type and volume of interventions in patients with CHD. Collegiality was realized by conducting an interdisciplinary neonatal cardiological consultation, the composition of which is regulated by the Order "On Optimization of Specialized Surgical Care for Newborns with Congenital Heart Diseases" and includes specialists of various profiles and various institutions: pediatric cardiologist, cardiac surgeon, resuscitator, anesthetist, neonatologist, doctor, neonatologist, doctor owning the method of echocardiography in children. New technologies for surgical treatment of children with critical CHD have been introduced in the CPPCS in Almaty, which significantly reduced the risks of worsening conditions associated with prolonged transport to cardiocenters (Table 1.)

Table 1 Stages of assisting newborn children with critical CHD in the CPPCS, Almaty

\begin{tabular}{cc}
\hline Prenatal stage MC: & $\begin{array}{c}\text { Echocardiography of the fetus in the CPPCS, Almaty } \\
\text { Dynamic monitoring of pregnant women with fetal } \\
\text { CHD in the CPPCS, Almaty }\end{array}$ \\
\hline Neonatal stage MC: & $\begin{array}{c}\text { Delivery in the CPPCS, Almaty } \\
\text { Consultation neonatologist + pediatric cardiologist + pe- } \\
\text { diatric cardiac surgeon and resuscitator }\end{array}$ \\
\hline
\end{tabular}




\section{Cardiac Surgery Stage MC:}

New technologies in the CPPCS, Almaty for operating

newborns

Postoperative nursing and observation

For the period 2007-2010 281 newborns with CHD were observed; 119 children (42.3\%) had critical CHD. In the second period (2011-2018), 1,098 children under the age of 1 year were observed, 175 of which were newborns (15.9\%). Of the last 27 were limited to conservative treatment. Eight (29.6\%) of these patients died from hypoxia and / or heart failure, which were incompatible with life, as well as from congenital pathology of other organs and systems. In the remaining $148(81.7 \%)$ cases, various surgical interventions were performed, which is much more than in the compared group, consistent with data from other studies and indicates an improvement in the diagnosis of CHD and critical conditions in the neonatal period.

No statistically significant differences were found in the studied groups of newborns with critical CHD: in terms of sex ratio, number of premature babies, a history of pregnancy and the presence of respiratory distress syndrome at birth, body weight at birth, the presence of a combined pathology that affects the delivery of MC and clinical outcomes (infectious process, chromosomal abnormalities, multiple congenital malformations) (Table 2).

\begin{tabular}{|l|c|c|c|}
\hline \multicolumn{1}{|c|}{ Parameter } & $\begin{array}{c}\text { First group } \\
\text { (n=119) }\end{array}$ & $\begin{array}{c}\text { Second group } \\
\text { (n=148) }\end{array}$ & P* \\
\hline Sex: & $77(64,7)$ & $62(41,9)$ & 0,128 \\
- male (\%) & $42(35,3)$ & $86(58,1)$ & 0,128 \\
- female (\%) & $26,9 \pm 0,56$ & $27,9 \pm 0,59$ & 0,256 \\
\hline Mother age & $37,5 \pm 0,29$ & $37,6 \pm 0,32$ & 0,287 \\
\hline Gestational age at the time of birth, weeks & & & \\
\hline Full-term / premature babies: & $92(77,3)$ & $91(80,5)$ & 0,549 \\
full-term newborns (\%) & $27(22,7)$ & $22(19,5)$ & 0,549 \\
preterm infants (\%) & $2,931 \pm 0,078$ & $2,920 \pm 0,088$ & 0,913 \\
\hline Body weight at birth, kg & $22(18,5)$ & $18(15,9)$ & 0,728 \\
\hline Presence during pregnancy (\%): & $7(5,9)$ & $10(8,8)$ & 0,388 \\
- polyhydramnios & $15(12,6)$ & $15(13,3)$ & 0,881 \\
\hline - chronic pyelonephritis & $43(36,1)$ & $33(29,2)$ & 0,262 \\
\hline Moderate and severe asphyxia in childbirth (\%) & $5(4,2)$ & $6(5,3)$ & 0,694 \\
\hline Chromosomal abnormalities (\%) & $61(51,3)$ & $66(58,4)$ & 0,336 \\
\hline Concomitant infectious process (\%) & & & \\
\hline
\end{tabular}

Table 2. Clinical characteristics of groups

In the first group, intrauterine heart disease was suspected in $32.8 \%$ of children (average gestation period - 26.7 weeks), in the second group - $46.9 \%$ of patients (average gestation period - 25.7 weeks $)(p=0.028)$. Accordingly, the minimum gestational period at which CHD was detected perinatally in the fetus was 19.5 and 13.0 weeks, and the maximum was 40.0 and 34.0. The proportion of identified CHD during pregnancy up to 22 weeks (inclusive) was statistically significantly different in the two groups (5.9\% in the first; $16.8 \%$ in the second; $p=0.009$ ); the revealed patterns indicate an improvement in the quality of perinatal diagnosis of $\mathrm{CHD}$ (table 3 ). 


\begin{tabular}{|c|c|c|c|}
\hline Indicator & $\begin{array}{c}2007-2010 \\
(n=119)\end{array}$ & $\begin{array}{c}2011-2018 \\
(n=148)\end{array}$ & $\mathbf{P}$ \\
\hline Total children with CHD identified in utero (\%) & $39(32,8)$ & $69(46,6)$ & 0,028 \\
\hline $\begin{array}{l}\text { The minimum gestational age for the detection of CHD in utero, } \\
\text { weeks }\end{array}$ & 19,5 & 13 & \\
\hline $\begin{array}{l}\text { The maximum gestational age for the detection of CHD in utero, } \\
\text { weeks }\end{array}$ & 40 & 34 & \\
\hline The average gestational age for the detection of CHD in utero, weeks & $26,7 \pm 0,5$ & $25,7 \pm 0,6$ & 0,312 \\
\hline $\mathrm{CHD}$ revealed in utero up to 22 weeks of gestation (\%) & $7(5,9)$ & $25(16,8)$ & 0,009 \\
\hline
\end{tabular}

Table 3. The effectiveness of prenatal diagnosis of CHD

In the absence of a prenatal diagnosis of CHD $(67.2 \%$ in the first group, $53.4 \%$ in the second group), postnatal diagnosis was performed by specialists from neonatal departments of the maternity hospital and multidisciplinary children's hospitals with the mandatory participation of a pediatric cardiologist. It was revealed that hypoxemic syndrome in the second group was diagnosed in $36(3 \%)$ newborns with CHD, which is significantly more likely than in the first - in $16(13.4 \%)(p=0.001)$. Arterial hypoxemia is the most common condition requiring consultation with a pediatric cardiologist. The main causes leading to the development of cyanosis in newborns are CHD, pulmonary dysfunction, damage to the central nervous system. Violation of tissue oxygenation in newborns can be aggravated by the presence of fetal hemoglobin, which has an increased affinity for oxygen and with great difficulty releases oxygen in tissues than in adults, which proves the feasibility of differential diagnosis of hypoxemic syndrome in the neonatal period, determination of ductus dependence of CHD, topical diagnosis of cardiac defect. Differential diagnostics and a collegial approach to the management of newborns with suspected CHD revealed rare complex forms of CHD (aorto-pulmonary tunnel, membrane of the right atrium with atresia of the excretory section, diverticulum of the right ventricle) in the second group.

An analysis of conservative pathogenetic therapy showed that since 2011, the appointment of perlinganitis is significantly less common $(\mathrm{p}=0.0001)$. The purpose of inhibitors of angiotensin-converting enzymes of diuretics $(p=0.283)$, the frequency of application of mechanical ventilation ( $p=0.755)$ did not differ in both groups (Table 4$)$. Thus, an improvement in the quality of the topical diagnosis of CHD has affected the tactics of conservative pathogenetic therapy in newborns with critical CHD.

\begin{tabular}{|l|c|c|c|}
\hline \multicolumn{1}{|c|}{ Indicator (\%) } & $\begin{array}{c}\mathbf{2 0 0 7 - 2 0 1 0} \\
(\mathbf{n = 1 1 9 )}\end{array}$ & $\begin{array}{c}\mathbf{2 0 1 1 - 2 0 1 8} \\
(\mathbf{n = 1 4 8})\end{array}$ & $\mathbf{P}$ \\
\hline Perlinganite & $28(23,5)$ & $2(1,35)$ & 0,001 \\
\hline Prostaglandins & $41(34,5)$ & $51(45,1)$ & 0,098 \\
\hline Diuretics & $61(51,3)$ & $49(43,4)$ & 0,283 \\
\hline Angiotensin Converting Enzyme Inhibitors & $55(46,2)$ & $42(37,2)$ & 0,163 \\
\hline Mechanical ventilation & $46(38,7)$ & $45(39,8)$ & 0,755 \\
\hline
\end{tabular}

Table 4. Therapy in the conservative treatment of newborns with critical CHD in the preoperative stage

In the first group, at the preoperative stage, a heart surgeon examined 87 patients, which amounted to $73.1 \%$. In the second group, a neonatal cardiological consultation with a cardiac surgeon was conducted for 148 children $(100 \%)(p=0.004)$. The active participation of the cardiac surgeon in determining the tactics of managing a newborn with CHD 
has allowed a higher operational activity. So, in the first group, 47 (39.5\%) patients were operated on, and in the second $-148(100 \%)(p=0.001)$.

Hospital mortality at the preoperative stage in the group of newborns with CHD in 2007-2010. made up $21.0 \%$ of patients, in the second group $-7.1 \%(p=0.002)$.

\section{Discussion}

Meta-analysis Holland B.J. et all show that prenatal diagnosis of critical congenital heart disease improves preoperative neonatal survival. Newborns diagnosed postpartum were more likely to die from cardiovascular failure prior to elective cardiac surgery than infants with prenatal diagnosis. [15] Previous studies on surgical and postoperative outcomes did not show an increase in the survival rate of patients with prenatal diagnosis.[16-22]

In the case of the CPPCS of the city of Almaty, the use of a multidisciplinary approach, and the direct participation of a pediatric cardiologist / cardiac surgeon, shows a significant decrease in mortality. The peculiarities of the management of such newborns in the CPPCS may open up new possibilities for improving the therapy of newborns with $\mathrm{CHD}$. When planning future studies aimed at studying the management of CHD, a multidisciplinary approach should be taken into account in the selection of therapy for newborns.

\section{Conclusions}

New organizational approaches to delivering MC to newborns with CHD, formulated in Almaty, were developed with the opening of CPPCS. A clear algorithm for diagnosing CHD in newborns has been introduced and an interdisciplinary approach (neonatal cardiological consultation) has been implemented in deciding on management tactics, pathogenetic therapy, the timing and type of surgical intervention in newborns with critical CHD. Timely and adequate organization of MC in newborns with CHD had a significant reduction in mortality in critical $\mathrm{CHD}$ at the preoperative stage.

Author Contributions: Conceptualization, B.T. and A.A.; methodology, A.A and V.P..; software, A.A.; validation, A.A., B.T. and K.K.; formal analysis, K.K.; resources, B.T.; data curation, V.P.; writing-original draft preparation, A.A.; writing - review and editing, A.A.; supervision, A.A.; project administration, B.T..

All authors have read and agreed to the published version of the manuscript." Please turn to the CRediT taxonomy for the term explanation. Authorship must be limited to those who have contributed substantially to the work reported.

Funding: Not applicable

Institutional Review Board Statement: Not applicable

Informed Consent Statement: Not applicable

Written informed consent for publication must be obtained from participating patients who can be identified (including by the patients themselves). Please state "Written informed consent has been obtained from the patient(s) to publish this paper" if applicable.

Data Availability Statement: The data that support the findings of this study are available on request from the corresponding author. The data are not publicly available due to privacy or ethical restrictions.Acknowledgments: Not applicable

Conflicts of Interest: The authors declare no conflict of interest

\section{References}


1. Hoffman JIE, Kaplan S. The incidence of congenital heart disease. Journal of the American College of Cardiology 2002;39. https://doi.org/10.1016/S0735-1097(02)01886-7.

2. Reller MD, Strickland MJ, Riehle-Colarusso T, Mahle WT, Correa A. Prevalence of Congenital Heart Defects in Metropolitan Atlanta, 1998-2005. The Journal of Pediatrics 2008;153. https://doi.org/10.1016/j.jpeds.2008.05.059.

3. Howell HB, Zaccario M, Kazmi SH, Desai P, Sklamberg FE, Mally P. Neurodevelopmental outcomes of children with congenital heart disease: A review. Current Problems in Pediatric and Adolescent Health Care 2019;49. https://doi.org/10.1016/j.cppeds.2019.100685.

4. Sun R, Liu M, Lu L, Zheng Y, Zhang P. Congenital Heart Disease: Causes, Diagnosis, Symptoms, and Treatments. Cell Biochemistry and Biophysics 2015;72. https://doi.org/10.1007/s12013-015-0551-6.

5. Abu-Harb M, Hey E, Wren C. Death in infancy from unrecognised congenital heart disease. Archives of Disease in Childhood 1994;71. https://doi.org/10.1136/adc.71.1.3.

6. Richmond S, Wren C. Early diagnosis of congenital heart disease. Seminars in Neonatology 2001;6. https://doi.org/10.1053/siny.2000.0028.

7. Fahed AC, Gelb BD, Seidman JG, Seidman CE. Genetics of Congenital Heart Disease. Circulation Research $2013 ; 112$. https://doi.org/10.1161/CIRCRESAHA.112.300853.

8. Wren C, Richmond S, Donaldson L. Presentation of congenital heart disease in infancy: implications for routine examination. Archives of Disease in Childhood - Fetal and Neonatal Edition 1999;80. https://doi.org/10.1136/fn.80.1.F49.

9. Hillebrand M, Koschyk D, ter Hark P, Schüler H, Rybczynski M, Berger J, et al. Diagnostic accuracy study of routine echocardiography for bicuspid aortic valve: a retrospective study and meta-analysis. Cardiovascular Diagnosis and Therapy 2017;7. https://doi.org/10.21037/cdt.2017.05.03.

10. Dolbec K, Mick NW. Congenital Heart Disease. Emergency Medicine Clinics of North America 2011;29. https://doi.org/10.1016/j.emc.2011.08.005.

11. Mohsin M, Humayun KN, Atiq M. Clinical Screening for Congenital Heart Disease in Newborns at a Tertiary Care Hospital of a Developing Country. Cureus 2019. https://doi.org/10.7759/cureus.4808.

12. van der Bom T, Zomer AC, Zwinderman AH, Meijboom FJ, Bouma BJ, Mulder BJM. The changing epidemiology of congenital heart disease. Nature Reviews Cardiology 2011;8. https://doi.org/10.1038/nrcardio.2010.166.

13. KAZSTAT. Agency for Strategic planning and reforms of the Republic of Kazakhstan. Bureau of National statistics n.d. https://stat.gov.kz (accessed March 31, 2021).

14. Republican Center for Healthcare Development. Statistical compilations "Health of the population of the Republic of Kazakhstan and the activities of health care organizations" (Russ./Kaz.) n.d. http://rcrz.kz/index.php/ru/?option=com_content\&view=article\&id=973 (accessed April 2, 2021).

15. Holland BJ, Myers JA, Woods CR. Prenatal diagnosis of critical congenital heart disease reduces risk of death from cardiovascular compromise prior to planned neonatal cardiac surgery: a meta-analysis. Ultrasound in Obstetrics \& Gynecology 2015;45. https://doi.org/10.1002/uog.14882.

16. Kumar RK, Newburger JW, Gauvreau K, Kamenir SA, Hornberger LK. Comparison of outcome when hypoplastic left heart syndrome and transposition of the great arteries are diagnosed prenatally versus when diagnosis of these two conditions is made only postnatally. The American Journal of Cardiology 1999;83. https://doi.org/10.1016/S0002-9149(99)00172-1.

17. Mahle WT, Clancy RR, McGaurn SP, Goin JE, Clark BJ. Impact of Prenatal Diagnosis on Survival and Early Neurologic Morbidity in Neonates With the Hypoplastic Left Heart Syndrome. PEDIATRICS $2001 ; 107$. https://doi.org/10.1542/peds.107.6.1277.

18. Kipps AK, Feuille C, Azakie A, Hoffman JIE, Tabbutt S, Brook MM, et al. Prenatal Diagnosis of Hypoplastic Left Heart Syndrome in Current Era. The American Journal of Cardiology 2011;108. https://doi.org/10.1016/j.amjcard.2011.03.065.

19. Trento LU, Pruetz JD, Chang RK, Detterich J, Sklansky MS. Prenatal diagnosis of congenital heart disease: impact of mode of delivery on neonatal outcome. Prenatal Diagnosis 2012;32. https://doi.org/10.1002/pd.3991.

20. Levey A, Glickstein JS, Kleinman CS, Levasseur SM, Chen J, Gersony WM, et al. The Impact of Prenatal Diagnosis of Complex Congenital Heart Disease on Neonatal Outcomes. Pediatric Cardiology 2010;31. https://doi.org/10.1007/s00246-0109648-2.

21. Landis BJ, Levey A, Levasseur SM, Glickstein JS, Kleinman CS, Simpson LL, et al. Prenatal Diagnosis of Congenital Heart Disease and Birth Outcomes. Pediatric Cardiology 2013;34. https://doi.org/10.1007/s00246-012-0504-4.

22. Oster ME, Kim CH, Kusano AS, Cragan JD, Dressler P, Hales AR, et al. A Population-Based Study of the Association of Prenatal Diagnosis With Survival Rate for Infants With Congenital Heart Defects. The American Journal of Cardiology 2014;113. https://doi.org/10.1016/j.amjcard.2013.11.066. 